\title{
Hubungan Penggunaan Hair Styling terhadap Kejadian Dermatitis Seboroik pada Mahasiswa Laki-laki di Fakultas Kedokteran Universitas Sam Ratulangi
}

\author{
${ }^{1}$ Jonathan V. D. Kalalo, \\ ${ }^{2}$ Herry E. J. Pandeleke, \\ ${ }^{2}$ Shienty Gaspersz
}

\author{
${ }^{1}$ Program Studi Pendidikan Dokter Fakultas Kedokteran Universitas Sam Ratulangi Manado \\ ${ }^{2}$ Bagian/SMF Ilmu Kesehatan Kulit dan Kelamin Fakultas Kedokteran \\ Universitas Sam Ratulangi Manado \\ Email: jonathan.kalalo@yahoo.com
}

\begin{abstract}
Seborrheic dermatitis is a type of papulosquamous dermatitis with predilection in areas with many sebaceous glands, scalp, face, and body. This disease is associated with immunological disorders, but ieven more with Malassezia. Seborrheic dermatitis can occur in all age groups, but is usually separated into two age groups: infants and adults. Seborrheic dermatitis has many precipitating factors, especially high oil levels and humidity. One of the trigger factors is the use of hair styling which triggers the oil production on the surface of scalp as well as hair. The occurence of excessive oil on the scalp and hair long time can cause dandruff and irritation. This study was aimed to determine the relationship between hair styling and the incidence of seborrheic dermatitis in male students at Sam Ratulangi University in Manado. This was an analytical study with a cross sectional design. Data were obtained by using questionnaires and anamnesis. The results showed that of the 25 respondents, 9 students had dandruff and 16 students did not. The chi-square test analyzing the relationship between hair styling and the incidence of seborrhoic dermatitis obtained a $P$ value of 0.332. Conclusion: There is no significant relationship between hair styling use and the incidence of seborrheic dermatitis
\end{abstract}

Keywords: hair styling, seborrheic dermatitis, male college students

\begin{abstract}
Abstrak: Dermatitis seboroik adalah salah satu jenis dermatitis papuloskuamosa dengan predileksi di daerah yang banyak kelenjar sebasea, skalp, wajah dan badan. Penyakit ini sering dihubungkan dengan kelainan imunologi, namun lebih sering dihubungkan dengan jamur Malassezia. Dermatitis seboroik dapat terjadi pada semua kelompok usia, namun biasanya terpisah menjadi dua golongan usia yaitu bayi dan dewasa. Dermatitis seboroik memiliki banyak faktor pencetus, terutama kadar minyak yang tinggi dan kelembaban. Salah satu faktor pencetusnya ialah penggunaan hair styling berlebih yang memicu timbulnya minyak pada rambut. Munculnya minyak pada rambut yang terlampau lama dapat menimbulkan ketombe dan juga iritasi. Penelitian ini bertujuan untuk mengetahui hubungan pemakaian hair styling dengan kejadian dermatitis seboroik pada mahasiswa laki-laki Fakultas Kedokteran Universitas Sam Ratulangi Manado. Jenis penelitian ialah analitik dengan desain potong lintang. Data diperoleh berdasarkan kuesioner yang dibagikan dan anamnesis. Hasil penelitian mendapatkan total 25 responden terdiri dari 9 orang berketombe dan 16 orang tidak berketombe. Hasil uji korelasi chi-square terhadap hubungan antara penggunaan hair styling dengan kejadian dermatitis seboroik menunjukkan nilai $P=0,332$. Simpulan: Tidak terdapat hubungan bermakna antara penggunaan hair styling dengan kejadian dermatitis seboroik
\end{abstract}

Kata kunci: hair styling, dermatitis seboroik, mahasiswa laki-laki 
Dermatitis seboroik adalah salah satu jenis dermatitis papuloskuamosa dengan predileksi di daerah yang banyak kelenjar sebasea, skalp, wajah, dan badan. Penyakit ini dihubungkan dengan kelainan imunologi, namun lebih sering dihubungkan dengan jamur Malassezia. ${ }^{1}$

Dermatitis seboroik dapat terjadi pada semua kelompok usia, namun biasanya terpisah menjadi dua golongan usia yaitu bayi dan dewasa. Pada bayi, penyakit ini memuncak pada 3 bulan pertama, sedangkan pada dewasa saat usia 30 hingga 60 tahun. ${ }^{2}$

Pada negara maju seperti Amerika Serikat, prevalensi dermatitis seboroik berkisar $1-3 \%$ yang menyerang populasi umum, sedangkan 3-5\% terjadi pada dewasa muda. Dalam suatu penelitian yang pernah dilakukan secara acak pada anak usia 12-20 tahun di Indonesia, diperkirakan pravelensi dermatitis seboroik sebesar $10,17 \%$, sedangkan golongan usia 20 tahun ke atas prevalensi didapatkan sebesar 26,45\%. ${ }^{3}$ Angka insiden pada dermatitis seboroik ialah 1-3\% dari jumlah populasi pada umumnya. Laki-laki lebih rentan terkena dermatitis seboroik dibanding perempuan pada semua rentang usia yang menunjukkan adanya kemungkinan hubungan dermatitis seboroik dengan hormon seks seperti androgen. ${ }^{4}$

Di Kota Manado sendiri, lebih tepatnya di RSUP Prof. Dr. R. D. Kandou data dermatitis seboroik periode Januari Desember 2012 terdapat 134 kasus (3,3\%), periode Januari - Desember 2015 terdapat 91 kasus $(2,2 \%)$. Pada kedua data di atas ditemukan pula bahwa dermatitis seboroik lebih banyak menyerang kelompok usia 4564 tahun.

Dermatitis seboroik memiliki banyak faktor pencetus, terutama kadar minyak yang tinggi dan kelembaban. Melihat kecenderungan jaman sekarang anak muda yang ingin tampil rapi sehingga kerap mencoba hal hal baru yang dapat membuat mereka terlihat lebih rapi. Salah satu yang cukup digandrungi ialah penggunaan hair styling. Hair styling memiliki beberapa tipe seperti oil-based, water-based, wax, clay, dan hair spray. Penggunaan hair styling ini memang mampu membuat penampilan menjadi lebih baik namun penggunaan hair styling yang berlebih merupakan salah satu faktor pemicu timbulnya minyak pada rambut. Munculnya minyak pada rambut yang terlampau lama dapat menimbulkan ketombe dan juga iritasi. Kebersihan rambut juga berperan disini. Jika rambut tidak sering dibersihkan maka dermatitis seboroik akan muncul akibat manifestasi dari ketombe.

\section{METODE PENELITIAN}

Penelitian ini bersifat analitik dengan desain potong lintang untuk mengetahui ada tidaknya pengaruh penggunaan hair styling terhadap kejadian dermatitis seboroik. Responden penelitian ini ialah mahasiswa angkatan 2015-2016 Fakultas Kedokteran Unsrat yang diambil dengan metode total sampling yang memenuhi kriteria inklusi. Variabel bebas penelitian ini ialah hair styling. sedangkan variabel terikat ialah kejadian dermatitis seboroik

\section{HASIL PENELITIAN}

Tabel 1 memperlihatkan distribusi usia dari total 25 orang responden. Mayoritas responden berusia 20-24 tahun, yaitu sebanyak 22 orang (88\%), diikuti responden berusia 15-19 tahun.

Tabel 1. Distribusi responden berdasarkan usia

\begin{tabular}{ccc}
\hline $\begin{array}{c}\text { Usia } \\
\text { tahun) }\end{array}$ & $\mathbf{N}$ & $\%$ \\
\hline $15-19$ & 3 & 12 \\
$20-24$ & 22 & 88 \\
Total & 25 & 100 \\
\hline
\end{tabular}

Tabel 2 menunjukkan distribusi jenis hair styling yang digunakan oleh responden. Dari total 25 responden, terdapat 16 orang (64\%) yang menggunakan pomade, 7 orang $(28 \%)$ yang menggunakan wax, dan 2 orang $(8 \%)$ yang menggunakan clay.

Tabel 3 memperlihatkan distribusi timbulnya ketombe akibat penggunaan hair styling. Terdapat 9 responden $(36 \%)$ yang berketombe sedangkan 16 responden $(64 \%)$ tidak berketombe. 
Tabel 2. Distribusi jumlah pengguna hair styling yang digunakan berdasarkan jenis

\begin{tabular}{lcc}
\hline Jenis hair styling & N & \% \\
\hline Pomade & 16 & 64 \\
Wax & 7 & 28 \\
Clay & 2 & 8 \\
Total & 25 & 100 \\
\hline
\end{tabular}

Tabel 3. Distribusi timbulnya ketombe akibat penggunaan hair styling

\begin{tabular}{ccc}
\hline Berketombe & $\mathbf{N}$ & $\mathbf{\%}$ \\
\hline Ya & 9 & 36 \\
Tidak & 16 & 64 \\
Total & 25 & 100 \\
\hline
\end{tabular}

Tabel 4 memperlihatkan gambaran lama pemakaian hair styling. Dari total 25 responden, pada pemakaian $<1$ tahun terdapat 2 orang berketombe (8\%); pada lama pemakaian 1-3 tahun terdapat 3 orang (12\%) berketombe; dan pada lama pemakaian 4-6 tahun terdapat 20 orang berketombe $(80 \%)$.

Tabel 4. Gambaran lama pemakaian hair styling

\begin{tabular}{lcc}
\hline Lama pemakaian & $\mathbf{N}$ & $\mathbf{\%}$ \\
\hline$<1$ tahun & 2 & 8 \\
1-3 tahun & 3 & 12 \\
4-6 tahun & 20 & 80 \\
Total & 25 & 100 \\
\hline
\end{tabular}

Tabel 5 menyajikan gambaran frekuensi cuci rambut. Pada frekuensi cuci rambut satu hari sekali terdapat 11 responden (44\%), sedangkan pada frekuensi cuci rambut dua kali sehari terdapat 7 responden (28\%), dan pada dua hari sekali terdapat 7 responden $(28 \%)$.

Tabel 5. Gambaran frekuensi cuci rambut

\begin{tabular}{lcc}
\hline Frekuensi cuci rambut & N & \% \\
\hline Satu hari sekali & 11 & 44 \\
Dua kali sehari & 7 & 28 \\
Dua hari sekali & 7 & 28 \\
Total & 25 & 100 \\
\hline
\end{tabular}

Tabel 6 menampilkan distribusi jenis hair styling yang menyebabkan ketombe. Dari total 25 responden, terdapat 4 orang
(57,15\%) pengguna pomade yang berketombe, 3 orang $(42,85 \%)$ pengguna wax yang berketombe, sedangkan pengguna clay tidak ada yang berketombe.

Tabel 6. Distribusi jenis hair styling yang menyebabkan ketombe

\begin{tabular}{lcc}
\hline Jenis hair styling & N & \% \\
\hline Pomade & 4 & 57,15 \\
Wax & 3 & 42,85 \\
Clay & 0 & 0 \\
Total & 7 & 100 \\
\hline
\end{tabular}

Tabel 7 menyajikan gambaran lama pemakaian hair styling. Dari total 25 responden, pada pemakaian $<1$ tahun terdapat 1 orang $(11,11 \%)$ yang berketombe, pada lama pemakian 1-3 tahun terdapat 1 orang $(11,11 \%)$ berketombe, dan pada lama pemakaian 4-6 tahun terdapat 7 orang $(77,78 \%)$ yang berketombe.

Tabel 7. Gambaran lama pemakaian hair styling

\begin{tabular}{lcc}
\hline Lama pemakaian & $\mathbf{N}$ & $\mathbf{\%}$ \\
\hline$<1$ tahun & 1 & 11,11 \\
1-3 tahun & 1 & 11,11 \\
4-6 tahun & 7 & 77,78 \\
Total & 9 & 100 \\
\hline
\end{tabular}

Tabel 8 memperlihatkan gambaran frekuensi cuci rambut pada responden yang berketombe. Pada frekuensi cuci rambut satu hari sekali terdapat 2 orang $(22,22 \%)$ berketombe, sedangkan pada frekuensi cuci rambut dua kali sehari terdapat 3 orang $(33,33 \%)$ berketombe, dan pada dua hari sekali terdapat 4 orang $(44,45 \%)$ berketombe.

Tabel 8. Gambaran frekuensi cuci rambut pada responden yang berketombe

\begin{tabular}{|c|c|c|c|}
\hline $\begin{array}{l}\text { Frekuensi } \\
\text { Rambut } \\
\end{array}$ & Cuci & $\mathbf{N}$ & $\%$ \\
\hline Satu hari sekali & & 2 & 22,22 \\
\hline Dua kali sehari & & 3 & 33,33 \\
\hline Dua hari sekali & & 4 & 44,45 \\
\hline Total & & 9 & 100 \\
\hline
\end{tabular}

Dari 25 responden yang diteliti didapatkan 9 responden berketombe dan 16 
responden tidak berketombe. Pada pengguna hair styling yang tergolong sering (>15 kali dalam 1 bulan) terdapat 6 responden $(40 \%)$ yang berketombe. Pada pengguna hair styling yang tergolong jarang (15 kali< dalam 1 bulan) terdapat 3 orang (30\%) yang berketombe dan 7 orang yang tidak berketombe.

Tabel 9. Distribusi pembagian jumlah pengguna hair styling yang berketombe berdasarkan penggunaan per bulan

\begin{tabular}{lcccc}
\hline \multirow{2}{*}{ Berketombe } & \multicolumn{4}{c}{$\begin{array}{c}\text { Penggunaan hair styling } \\
\text { per bulan }\end{array}$} \\
\cline { 2 - 5 } & $>15$ & $\%$ & $<15$ & $\%$ \\
\hline Ya & 6 & 40 & 3 & 30 \\
Tidak & 9 & 60 & 7 & 70 \\
Total & 15 & 100 & 10 & 100 \\
\hline
\end{tabular}

Berdasarkan hasil uji bivariat menggunakan uji chi-square yang melibatkan 2 variabel yaitu penggunaan hair styling dan dermatitis seboroik didapatkan bahwa 9 orang berketombe sedangkan 16 orang tidak berketombe dengan nilai signifikasi sig. (2-tailed) sebesar 0,332 (>0,05) yang menunjukkan tidak terdapat hubungan bermakna antara penggunaan hair styling dengan kejadian dermatitis seboroik pada mahasiswa laki-laki di Fakultas Kedokteran Universitas Sam Ratulangi Manado.

\section{BAHASAN}

Hasil penelitian ini menunjukkan dari total 25 orang responden, mayoritas responden berusia 20-24 tahun (88\%), diikuti responden berusia 15-19 tahun (12\%) (Tabel 1). Penelitian yang dilakukan oleh Bologna et $\mathrm{al}^{6}$ menyatakan bahwa dermatitis seboroik sering terjadi pada bayi berusia 3-12 bulan yang dapat sembuh dengan sendirinya seiring bertambahnya usia. Dermatitis seboroik sering menyerang pada usia 40 tahun ke atas, namun pada kasus dewasa lebih sering disebabkan oleh kelainan imunologi seperti HIV/AIDS. $^{7}$

Banyak orang sering menggunakan produk hair styling untuk menunjang penampilan. Terdapat beberapa jenis bahan hair styling yang sering digunakan yaitu pomade, clay, dan wax. Menurut hasil penelitian dari total 25 responden, terdapat 16 orang $(64 \%)$ yang menggunakan pomade, 4 di antaranya berketombe; 7 orang (28\%) yang menggunakan wax, 3 di antaranya berketombe; dan 2 orang $(8 \%)$ yang menggunakan clay, keduanya tidak berketombe (Tabel 6). Tingginya penggunaan pomade ini dikarenakan karena pomade membuat rambut lebih lembab, licin, dan mengkilap lebih lama dibandingkan dengan produk hair styling yang lain. ${ }^{7}$ Pada penelitian ini rerata lama pemakaian hair styling ini mencapai 4-6 tahun, dan didapatkan 7 orang yang berketombe. Penggunaan hair styling memiliki pengaruh pada rambut, karena penggunaan hair styling terutama jenis pomade melembabkan rambut yang dapat memicu timbulnya jamur Malassezia. Menurut penelitian Utami et al, ${ }^{9}$ semakin banyak volume pomade yang digunakan dan semakin lama penggunaannya dapat memicunya timbulnya ketombe, namun pada penelitian ini penggunaan hair styling tidak menimbulkan keluhan ketombe.

Hasil penelitian menunjukkan bahwa pada frekuensi cuci rambut satu hari sekali terdapat 2 orang berketombe dan 9 orang tidak berketombe, sedangkan pada frekuensi cuci rambut dua kali sehari terdapat 3 orang berketombe dan 4 orang tidak berketombe, dan pada dua hari sekali terdapat 4 orang berketombe dan 3 orang tidak berketombe (Tabel 8). Menurut D'Souza dan Rathi, ${ }^{10}$ frekuensi cuci rambut bergantung kepada jenis rambut apakah rambut normal, rambut kering, atau sedang menggunakan produk hair styling. Pengguna hair styling disarankan menggunakan deep cleaning shampoo seminggu sekali karena pada jenis sampo ini terdapat lauryl sulfate yang dapat mengangkat polimerpolimer pada rambut. Penggunaan lauryl sulfate dapat membersihkan minyak pada kulit, namun dapat menyebabkan iritasi.

Hasil uji chi-square yang melibatkan 2 variabel yaitu penggunaan hair styling dan dermatitis seboroik mendapatkan nilai signifikasi sig. (2-tailed) sebesar 0,332 
$(>0,05)$ yang menunjukkan tidak terdapat hubungan bermakna antara penggunaan hair styling dengan kejadian dermatitis seboroik pada mahasiswa laki-laki di Fakultas Kedokteran Universitas Sam Ratulangi Manado. Hasil penelitian ini tidak selaras dengan penelitian oleh Utami et $\mathrm{al}^{9}$ yang menyatakan bahwa terdapat hubungan penggunaan pomade dengan terjadinya ketombe. Penggunaan pomade dapat menyebabkan ketombe karena mengandung petroleum jelly dan bees wax. Volume dan lama penggunaan pomade yang membuat rambut dalam keadaan lembab menjadi salah satu faktor yang dapat menyebabkan terjadinya ketombe. ${ }^{10}$

\section{SIMPULAN}

Berdasarkan hasil penelitian ini dapat disimpulkan bahwa tidak terdapat hubungan bermakna antara pengunaan hair styling dengan kejadian dermatitis seboroik pada mahasiswa laki-laki di Fakultas Kedokteran Universitas Sam Ratulangi Manado.

\section{DAFTAR PUSTAKA}

1. Jacoeb TNA. Dermatitis seboroik. In: Menaldi SLS, editor. Ilmu Penyakit Kulit dan Kelamin (7th ed). Jakarta: Badan Penerbit FKUI, 2015.

2. Widaty S, Marina A. Pilihan pengobatan jangka panjang pada dermatitis seboroik. Jakarta: Departemen Ilmu Kesehatan Kulit dan Kelamin Fakultas Kedokteran Universitas Indonesia,
2016; p. 21, 153-9.

3. Yuan SH, Zhang H, Chen QL, Shao-hui Y, Hong $\mathbf{Z}$, et al The Prevalence and risk factors analysis of adolescent seborrheic dermatitis in tropical and swotropical area. The Chinese Journal of Dermatovenerology. 2008-12

4. Sampaio AL, Mameri AC, Vargas TJ, Ramos-e-Silva M, Nunes AP, Carneiro SC. Seborrheic dermatitis. An Bras Dermatol. 2011;86(6):106171.

5. Malak S, Kandou RT, Pandeleke TA. Profil dermatitis seboroik di Poli-klinik Kulit dan Kelamin RSUP Prof. Dr. R. D. Kandou Manado periode JanuariDesember 2015. eCl. 2015; 4(1):202-6.

6. Bologna JL, Jorizzo JL, Rapini RP, Callen JP, Horn TD, Mancini AJ, et al. Dermatology (2nd ed). Elsevier, 2008

7. Gayatri L, Barakbah J. Dermatitis Seboroik pada HIV/AIDS. Surabaya: Fakultas Kedokteran Universitas Airlangga; 2011.

8. Shafat YA. Proses pembuatan pomade dari minyak kelapa menggunakan alat screw press [Undegraduate thesis]. Semarang: Universitas Diponegoro; 2015.

9. Utami AR, Sukohar A, Setiawan G, Morfi CW. Pengaruh penggunaan pomade terhadap kejadian ketombe pada remaja pria. Majority. 2018;7(2):187-92.

10. D'Souza P, Rathi SK. Shampoo and conditioners: What a dermatologist should know? Indian J Dermatol. 2015;60(3):248-54. 